UCRL-JC-123482

PREPRINT

\title{
A Desiccant Dehumidifier for Electric Vehicle Heating +
}

\author{
Salvador M. Aceves, J. Ray Smith
}

RECEIVED

MAY O 21996

OSTI

This paper was prepared for submittal to

Symposium on Thermodynamics and the Design, Analysis and Improvement of Energy Systems, International Mechanical Engineering Congress and Exposition:

The Winter Annual Meeting of ASME

Atlanta, GA

November 17-22, 1996

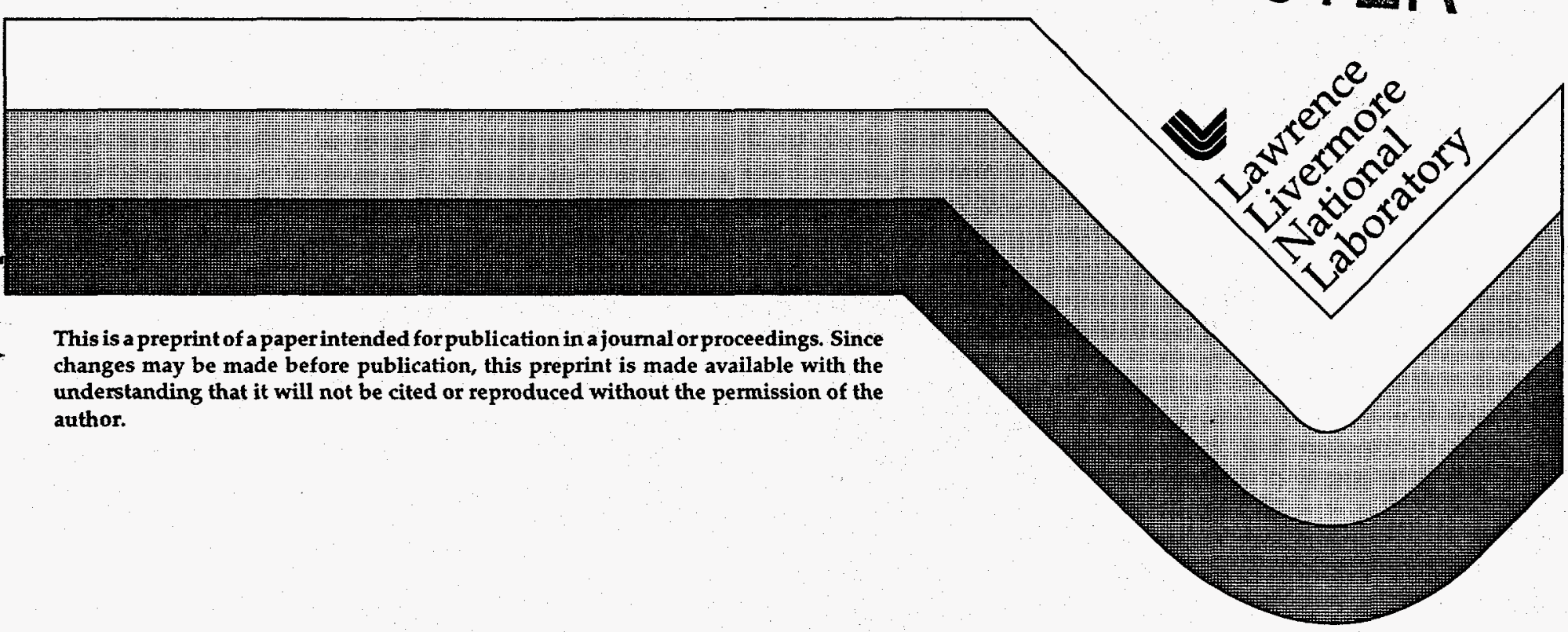

permission of the changes may be made before publication, this preprint is made available with the understanding that it will not be cited or reproduced without the permission of the author.

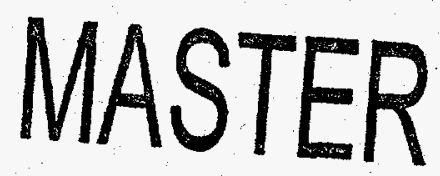




\section{DISCLAIMER}

This document was prepared as an account of work sponsored by an agency of the United States Government. Neither the United States Government nor the University of California nor any of their employees, makes any warranty, express or implied, or assumes any legal liability or responsibility for the accuracy, completeness, or usefulness of any information, apparatus, product, or process disclosed, or represents that its use would not infringe privately owned rights. Reference herein to any specific commercial product, process, or service by trade name, trademark, manufacturer, or otherwise, does not necessarily constitute or imply its endorsement, recommendation, or favoring by the United States Government or the University of California. The views and opinions of authors expressed herein do not necessarily state or reflect those of the United States Government or the University of California, and shall not be used for advertising or product endorsement purposes. 


\title{
A Desiccant Dehumidifier for Electric Vehicle Heating*
}

\author{
by
}

\author{
Salvador M. Aceves and J. Ray Smith \\ Lawrence Livermore National Laboratory \\ Livermore, CA 94551
}

\begin{abstract}
Vehicle heating requires a substantial amount of energy. Engines in conventional cars produce enough waste heat to provide comfort heating and defogging/defrosting, even under very extreme conditions. Electric vehicles (EVs), however, generate little waste heat. Using battery energy for heating may consume a substantial fraction of the energy storage capacity, reducing the vehicle range, which is one of the most important parameters in determining EV acceptability.
\end{abstract}

Water vapor generated by the vehicle passengers is in large part responsible for the high heating loads existing in vehicles. In cold climates, the generation of water vapor inside the car may result in water condensation on the windows, diminishing visibility. Two strategies are commonly used to avoid condensation on windows: 1) The windows are kept warm; and 2) A substantial amount of ambient air is introduced in the vehicle. It is clear that either of these strategies results in a substantial heating load. These strategies are often used in combination, and a trade-off exists between them. If the temperature of the windows is decreased, the ventilation rate has to be increased. Reducing the ventilation rate requires an increase of the temperature of the windows. Otherwise, condensation occurs.

An alternative procedure to avoid condensation is the use of a desiccant dehumidifier. A dehumidifier adsorbs the water vapor generated by the passengers, avoiding condensation without requiring high window temperatures or ventilation rates. Window temperatures and ventilation rates can therefore be reduced simultaneously, resulting in a substantially lower heating load.

The present paper explores the dehumidifier heating concept. The paper is divided in two parts. The first part shows the energy savings that could be obtained by using this technology. The second part specifies the required characteristics and dimensions of the system.

*Work performed under the auspices of the U.S. Department of Energy by the Lawrence Livermore National Laboratory under Contract No. W-7405-Eng. 48. 
The results indicate that the desiccant system can reduce the steady-state heating load by $60 \%$ or more under typical conditions. The reduction in heating load is such that waste heat may be enough to provide the required heating under most ambient conditions. Desiccant system dimensions and weight appear reasonable for packaging in an EV.

Nomenclature

a,b,c dehumidifier external dimensions (Table 2)

$A_{w} \quad$ vehicle window area

$c_{p} \quad$ specific heat

d free height between desiccant plates

$e_{1}$ thickness of the desiccant layer

$e_{2}$ thickness of the aluminum plate

h heat transfer coefficient

$h_{m} \quad$ mass transfer coefficient

k thermal conductivity

$\mathrm{m}_{\mathrm{a}}$ air mass flow rate

n number of parallel plates in dehumidifier

$\mathrm{q}_{\mathrm{d}} \quad$ desiccant heat of adsorption

Q heating load in vehicle

t time

$T$ temperature

v velocity

w water content of desiccant, $\mathrm{kg} / \mathrm{kg}$

$x$ coordinate measured along the dehumidifier air flow direction

Y humidity ratio, $\mathrm{kg}$ water $/ \mathrm{kg}$ air

$\rho$. density

subscripts

a air

amb ambient

c conduction

d desiccant

in inside vehicle

m metal

min minimum

ms metabolic, sensible

out outside vehicle

$v \quad$ ventilation

w window 


\section{DISCLAIMER}

Portions of this document may be illegible in electronic image products. Images are produced from the best available original document. 



\section{INTRODUCTION}

Previous researchers (Ikeda et al., 1990; Dieckmann and Mallory, 1992; Kyle and Sullivan, 1993; Wiczalek, 1993) have indicated the difficulty associated with providing electric vehicle (EV) climate control. Electric vehicle batteries carry only small amounts of energy (typically about a half gallon of gasoline energy equivalent), and climate control may consume a significant amount of this energy, resulting in a reduced vehicle range.

Most research up to date deals with the problem of EV cooling. It has been found (Dieckmann and Mallory, 1991; Aceves, 1996) that substantial reductions in the cooling load can be achieved by using heat-reflective or heat-absorptive windows, while simultaneously reducing outdoor air ventilation levels to the minimum recommended value (ASHRAE, 1981).

Electric vehicle heating has been recognized as a more difficult problem, mainly due to the high thermal loads associated with defogging (Kyle and Sullivan, 1993). Generation of water vapor by vehicle passengers may result in water condensation on the windows, reducing visibility. Two strategies are commonly used to avoid condensation on windows: 1) The windows are kept warm; and 2) A substantial amount of ambient air is introduced in the vehicle. Either of these strategies results in a substantial heating load. These strategies are often used in combination, and a trade-off exists between them, which makes it impossible to reduce them simultaneously. The resulting heating load often falls in the range of 2 to $4 \mathrm{~kW}$, depending on ambient temperature and vehicle characteristics.

Other difficulties associated with cold weather operation of EVs have been recently pointed out by the car manufacturers (Freedman and Zemke, 1995; Burba et al., 1995). These include: the increase in tire rolling losses, the reduction of lead-acid battery energy capacity, the increase of lubricant viscosity, and the increase in air density, which increases the aerodynamic drag.

Recognizing the difficulties associated with EV heating, the California Air Resources Board (CARB), which has mandated zero emission vehicles (ZEVs), has established that a vehicle can be considered a $Z E V$ if it uses combustion heating at ambient temperatures below $5^{\circ} \mathrm{C}$, provided that the vehicle is otherwise a ZEV (Automotive News, 1993). While combustion can provide the required heating, some difficulties exist. These include: the substantial size and weight of these systems; the need to service and fuel two energy sources; and the possible generation of pollutants by the combustion heater.

The alternative to combustion heating is to use a combination of waste heat recovery, heat pump operation, and electric resistance heating. Average waste heat available in the GM Impact EV has been estimated at $700 \mathrm{~W}$ (Dieckmann and Mallory, 1991). This is not 
enough to cover the heating needs, even at relatively mild temperatures $\left(10^{\circ} \mathrm{C}\right)$. The rest has to be provided by heat pump and electric resistance heating. Considering that the heat pump COP drops drastically as the temperature falls, it is expected that a substantial amount of energy is required for providing heating.

This paper explores the possibility of using a desiccant dehumidifier for reducing the heating load. A dehumidifier adsorbs the water vapor generated by the passengers, avoiding condensation without requiring high window temperatures or ventilation rates. Window temperatures and ventilation rates can therefore be reduced simultaneously, resulting in a substantially lower heating load. The heat of adsorption is also liberated during vehicle operation, contributing to heat the EV. Regeneration of the desiccant can take place while the vehicle is being charged, so that the system can operate without consuming any energy out of the battery, except for fan operation.

Dehumidification heating has been recently studied (Suzuki and Takahashi, 1995; Suzuki and Ishii, 1996). These researchers use a heat pump system for dehumidification. Air inside the car is circulated through the heat pump evaporator, which dehumidifies it while simultaneously cooling it down. The air is then circulated through the condenser, which heats the air to a temperature high enough to meet the heating load. The cooling and reheating of the air results in a low COP. However, the system has shown to outperform conventional systems in keeping the vehicle at comfort conditions and the windows clear. The fact that the system remains competitive despite the low COP is an indication of the merits of dehumidification heating.

Other possible applications (not analyzed in this paper) of desiccant dehumidifiers include heating of range extenders and series hybrid vehicles. Range extenders are electric vehicles which have a small engine to provide an unlimited range. The engine usually does not operate until the vehicle meets an all-electric range, which may be substantial. Therefore, the vehicle cannot use engine waste heat during a significant part of its period of use. Series hybrid vehicles operate with an engine in an on-off mode to keep an energy storage device at an appropriate level of charge. The engine may be off for most of the time, and waste heat is unlikely to provide all the required heating (Aceves and Smith, 1995). The dehumidifier can also be applied for EV air conditioning, by reducing the latent load, which is a major part of the cooling load in regions of humid climate. However, application of the dehumidifier for cooling is complicated by the need of rejecting the heat of adsorption outside the car.

The present paper explores the desiccant heating concept. The paper is divided in two main sections. The first shows an analysis of the heating loads in an EV, and how these can be reduced by using the dehumidifier. The second section shows the characteristics and dimensions of the dehumidifier that can provide the required performance in an EV. 


\section{HEATING LOAD CALCULATION}

Table 1 lists the main vehicle characteristics and assumptions used for the heating load calculation . Four passengers and saturated outdoor air are selected as the most demanding conditions that are likely to be encountered. Metabolic loads and minimum make-up air ventilation rates are obtained from ASHRAE (1981). Window area was directly measured in a subcompact car. Conduction load through the car body (without including windows) is estimated as $400 \mathrm{~W}$ for a $0^{\circ} \mathrm{C}$ ambient temperature (Aceves, 1996). Conduction load at other temperatures is calculated by assuming that it is proportional to the temperature difference between the ambient and indoor temperatures. Outdoor and indoor heat transfer coefficients are calculated from the correlations given by Shimizu et al., 1982. An average EV speed of $70 \mathrm{~km} / \mathrm{h}$ is assumed. Shimizu et al. consider only heat transfer due to air flow around the car, and the value selected for the heat transfer coefficient (60 $\mathrm{W} / \mathrm{m}^{2 \circ} \mathrm{C}$ ) may be low for some weather conditions such as rain. No data could be obtained to evaluate heat transfer coefficients under these conditions. The inside heat transfer coefficient agrees well with the value used by Dieckmann and Mallory (1991).

Heat transfer calculations assume that the car is at comfort, steady-state conditions. Previous research has shown the importance of transient loads in the heating load calculation (Kyle and Sullivan, 1993). However, many manufacturers are providing EVs with a preheating option, which can be used to set the car at comfort conditions at the time when the driver is planning to use the car (Wyczalek, 1993), therefore eliminating the transient load. Preheating uses no energy out of the battery and therefore has no negative effect on vehicle range.

Heating load is calculated as follows:

$Q=Q_{c}+Q_{v}+Q_{w}-Q_{m, s}$

where $Q_{c}$ is the conduction load through the car body, $Q_{m, s}$ is the metabolic sensible load, and $Q_{v}$ and $Q_{w}$ are respectively the ventilation load and the heat transfer through the windows. Defrosting loads are not included because there is no need to defrost a preheated car. Even if the car is not preheated, defrosting has to be done only once, and its contribution to the total energy consumption is usually small (Kyle and Sullivan, 1993). Ventilation load and window heat transfer are given by the following equations:

$Q_{v}=m_{a} c_{p, a}\left(T_{i n}-T_{a m b}\right)$

$Q_{w}=h_{\text {out }} A_{w}\left(T_{w}-T_{a m b}\right)$ 
Equations (2) and (3) are related by the requirement of keeping the windows clear at all times. The window temperature, $T_{w}$, is not an independent variable. Instead, it is a function of the ventilation rate, $m_{2}$. The ventilation rate determines the humidity ratio inside the car, and $T_{w}$ has to be at least equal to the dew point temperature to avoid condensation. In this analysis $T_{w}$ is made $2^{\circ} \mathrm{C}$ higher than the dew point temperature inside the car, to avoid condensation due to inhomogeneities in the water vapor distribution.

Figure 1 shows window temperature required to avoid condensation as a function of air flow rate, for an ambient temperature of $5^{\circ} \mathrm{C}$. Figure 2 shows ventilation heating load, window heat transfer, and total heating load, as a function of ventilation rate. The figure shows the trade-off between the two contributions, and also illustrates the existence of a ventilation rate for which a minimum overall heating load is obtained. The optimum ventilation rate can be obtained for any ambient temperature, and the minimum overall heating load can then be determined. Optimum ventilation rates are of the order of 0.05 $\mathrm{kg} / \mathrm{s}$, and are a slowly increasing function of ambient temperature. Figure 3 shows the minimum total heating load, along with the ventilation and window conduction contributions, as a function of ambient temperature. The minimum overall heating load has values from almost $2000 \mathrm{~W}$ at $10^{\circ} \mathrm{C}$ to as much as $4200 \mathrm{~W}$ at $-10^{\circ} \mathrm{C}$. It is clear that an EV with an efficient power train, such as the Impact, does not generate enough waste heat to provide heating, and heat pump and resistance heating are necessary, consuming a substantial amount of the total battery energy.

Heating loads can be reduced by installing a regenerative heat exchanger (Kyle and Sullivan, 1993). A regenerator uses the enthalpy of the air flowing out of the car to preheat the outdoor make-up ventilation air. Regeneration reduces the required heating per unit mass of outdoor air. The trade-off between ventilation and window heat transfer still exists, but the optimum make-up ventilation rate increases. Three values for the regenerator effectiveness are selected $(50 \%, 60 \%$ and $70 \%)$, and the corresponding optimum ventilation rates are approximately $0.08,0.09$, and $0.1 \mathrm{~kg} / \mathrm{s}$ respectively. Figure 4 shows the minimum total heating loads as a function of ambient temperature, for the case with no regeneration (from Figure 3), as well as for the three selected values of the regenerator effectiveness. The results indicate that the use of a regenerator reduces the heating loads by about $30 \%$. Regenerator volumes have been calculated assuming that a 50 $\mathrm{W}$ fan is used in each of the two sides. The volumes are: 4,8 and 18 liters respectively for the $50 \%, 60 \%$ and $70 \%$ regenerator effectiveness. Raising the effectiveness beyond $70 \%$ requires a substantial increase in size or fan power (or both) to produce only a marginal decrease in heating load (Kays and London, 1964). Higher effectiveness values are therefore not considered. 
For the EV with a dehumidifier, heating load can be calculated as follows:

$Q=Q_{c}+Q_{v}+Q_{w}-Q_{m, s}-Q_{d}$

where the new term $Q_{d}$ represents the energy released by the desiccant when it adsorbs humidity. For a silica-gel desiccant, and for the rate of humidity generation inside the car, $Q_{d}$ is $310 \mathrm{~W}$. The terms $Q_{c}$ and $Q_{m, s}$ have the same values as for the EV with no dehumidifier. Ventilation and window heat transfer loads are now given by the following equations:

$Q_{v}=m_{2, \min } c_{p, a}\left(T_{i n}-T_{a m b}\right)$

$Q_{w}=h_{\text {in }} A_{w}\left(T_{i n}-T_{a m b}\right)$

The desiccant system allows the use of the minimum recommended make-up air mass flow rate, resulting in a low ventilation load. Windows can be kept cold, at a temperature that approaches the ambient temperature. Heat loss through windows is limited by convection inside the car. The heat transfer coefficient, $h_{\text {in, }}$, is low, resulting in low window heat transfer.

Figure 5 shows the heating loads for the EV equipped with the dehumidifier. Minimum heating load for the vehicle with no dehumidifier is also included for comparison (from Figure 3). The advantages of dehumidification heating are evident. Heating load is only $1500 \mathrm{~W}$ at $-10^{\circ} \mathrm{C}(36 \%$ of the original $)$; and $400 \mathrm{~W}$ at $10^{\circ} \mathrm{C}(23 \%$ of the original $)$. Waste heat available in the GM impact is enough to heat the car for ambient temperatures down to $3^{\circ} \mathrm{C}$. Vehicles operated in mild weather may therefore need very little electric resistance or heat pump heating. Figure 5 also shows that regeneration can be used to decrease the heating load even further. For $70 \%$ regeneration, $700 \mathrm{~W}$ of waste heat is enough to cover the heating needs down to $-8^{\circ} \mathrm{C}$. Regenerator volume for this application is low, due to the reduced ventilation rate. Estimated volumes are: 2, 3 and 6 liters respectively for the $50 \%, 60 \%$ and $70 \%$ regenerator effectiveness, assuming two $50 \mathrm{~W}$ fans.

\section{DESICCANT DEHUMIDIFIER ANALYSIS}

Desiccant dehumidifiers have been studied in the past mainly as a method for providing heat-assisted air conditioning (Nimmo et al., 1993; Zheng et al., 1993). Some advantages of desiccant systems are: control of the humidity of air independently of its temperature; operation free of CFCs; elimination of high humidity conditions, which cause air quality problems and damage to materials; stability over many cycles; and benign environmental characteristics (Mei et al., 1992; Feustel et al., 1992). 
This section presents an analysis and conceptual design of a desiccant dehumidifier that can be used to avoid condensation on the windows of an EV. The dehumidifier adsorbs the humidity of the air inside the EV when heating is required. The desiccant is later regenerated by heating it with electric resistance heaters when the vehicle is being charged, without using any energy from the battery.

The dehumidifier is constructed as a series of parallel plates, with the air flowing in the space between the plates. Each plate is made of aluminum, with two layers of desiccant (silica gel) applied to its sides. A schematic of this configuration is shown in Figure 6. Silica gel is selected as the desiccant because it is inexpensive and readily available, and because its properties are well known. Aluminum is selected as the material for the plates because of the need to regenerate the desiccant with electricity. The high thermal conductivity of aluminum allows the use of few electric resistance heaters to reach the regeneration temperature without substantial temperature gradients.

Temperature gradients are not desirable during the regeneration process, but they help improve performance during the dehumidification phase. It has been established that a sharp desiccant temperature profile results in enhanced adsorption (Shelton, 1986). It is therefore recognized that better dehumidifier materials and configurations may exist, but a more detailed analysis of these topics is beyond the scope of this work.

The analysis assumes that the transport of heat and mass from the air stream to the desiccant is controlled by the air-side film resistance; and there are no significant temperature or concentration gradients across the thickness of the desiccant (Charoensupaya and Worek, 1988). The mass and energy conservation equations are obtained from Roy and Gidaspow (1974), with modifications to reflect the differences in geometry. Roy and Gidaspow have shown that the terms representing the thermal inertia of the flowing fluid are very small, and these have been neglected from the equations.

The equation of conservation of water mass in the air stream is,

$$
\rho_{\mathrm{a}} \mathrm{dv} \frac{\mathrm{dY_{ \textrm {a } }}}{\mathrm{dx}}=2 \mathrm{~h}_{\mathrm{m}}\left(\mathrm{Y}_{\mathrm{d}}-\mathrm{Y}_{\mathrm{a}}\right)
$$

where $Y_{a}$ represents the humidity ratio of the air ( $\mathrm{kg}$ water/ $\mathrm{kg}$ air), and $Y_{d}$ is the humidity ratio of air in equilibrium with the desiccant. 
The equation of conservation of water mass in the desiccant is,

$\rho_{d} e_{1} \frac{d w}{d t}=h_{m}\left(Y_{2}-Y_{d}\right)$

the equation of energy conservation for the air is,

$\rho_{\mathrm{a}} d v c_{\mathrm{p}, \mathrm{z}} \frac{d \mathrm{~T}_{\mathrm{z}}}{d x}=2 h\left(T_{d}-T_{\mathrm{a}}\right)$

and the equation of energy conservation in the silica gel/aluminum wall is,

$$
\left(2 \rho_{d} e_{1} c_{p, d}+\rho_{m} e_{2} c_{p, m}\right) \frac{\partial T_{d}}{\partial t}=2 h\left(T_{a}-T_{d}\right)+k_{m} e_{2} \frac{\partial^{2} T_{d}}{\partial x^{2}}+2 q_{d} h_{m}\left(Y_{a}-Y_{d}\right)
$$

where $q_{d}$ is the heat of adsorption of the desiccant. The analysis takes into account conduction along the wall in the metal but neglects it in the desiccant.

In addition to the previous equations, standard correlations are used for friction factor and heat transfer coefficient. The mass transfer coefficient is calculated by assuming a Lewis number of 1.0 (Kweller et al., 1991). The equilibrium correlations for silica gel are obtained from Dupont et al., 1994. The system of equations is solved by finite differences. The results are then used in the calculation of the humidity ratio inside the EV. The desiccant system is required to keep the humidity level below the saturation humidity at the window temperature (assumed to be equal to the outdoor temperature), during the normal operating period for the car (assumed as 2 hours).

The desiccant system is optimized for minimum volume, which is usually the greatest constraint in incorporating a component into a car. Optimization is done with an existing optimizer (Haney et al., 1992). The optimizer has been developed for the fusion energy program, and has been applied to complex problems of tokamak reactor design. The optimization of the desiccant dehumidifier considers four independent variables. Descriptions of these variables and their allowable ranges are given in Table 2. All the vehicle parameters listed in Table 1 are used in the calculation. The values of other dehumidifier parameters are listed in Table 3.

Two dehumidifiers are designed: one for an ambient temperature of $0^{\circ} \mathrm{C}$, and the other for $-10^{\circ} \mathrm{C}$. The results of the optimization are shown in Table 4 . Weight and volume of both dehumidifiers appear reasonable for packaging inside an EV. The results indicate that the 
dehumidifier avoids the disadvantages of a combustion heater and reduces the heating loads far lower than possible with a regenerator, without a significant penalty in weight or volume.

Upper and lower bounds are imposed on the dehumidifier dimensions $\mathrm{a}, \mathrm{b}$, and $\mathrm{c}$ to facilitate packaging, and the value of $\mathrm{c}$ is limited by the upper bound. The design for $-10^{\circ} \mathrm{C}$ has about twice the weight and volume as the design for $0^{\circ} \mathrm{C}$, because the humidity ratio has to be kept lower when the ambient temperature drops. Most of the water adsorbed is generated by the passengers. The design for $0^{\circ} \mathrm{C}$ adsorbs more water over the operating period because ambient air humidity ratio is higher at the higher temperature. Optimum designs have relatively large frontal areas and are relatively short. The Reynolds number is laminar in both cases.

Table 4 also lists the energy required for system regeneration. Regeneration is done when the vehicle is being charged, without consuming any energy out of the battery. The energy required for regeneration is small, especially when compared to the heating load reduction that results from using this system. Heating load reduction is calculated with respect to the conventional heating system with no regeneration, at the design temperature for each case, assuming a trip length of 2 hours. Dividing the heating load reduction by the energy required for regeneration results in an equivalent COP for this system, which has a value of almost 3 for a $0^{\circ} \mathrm{C}$ ambient temperature, and 3.3 for $-10^{\circ} \mathrm{C}$. The dehumidifier provides therefore not only a method for reducing heating loads, but also a procedure for reducing net energy consumption compared to conventional systems.

Figures 7 and 8 illustrate some of the results obtained from the analysis. Figure 7 shows the relative humidity of the air inside the car and the air flowing out of the dehumidifier, for the dehumidifier designed for $0^{\circ} \mathrm{C}$. Relative humidity is usually defined as the partial pressure of water divided by the partial pressure of water at saturated conditions, at the temperature of the air. In this case, however, condensation occurs at the windows, which have a substantially lower temperature than the indoor air. Therefore, the relative humidity presented in Figure 7 is calculated as partial pressure of water divided by partial pressure of water at saturated conditions, at the temperature of the windows. According to this definition, a relative humidity of less than $100 \%$ indicates that no condensation occurs on the windows.

Figure 7 shows that the dehumidifier reduces the relative humidity inside the car to less than $50 \%$ within the first minute of operation. From this point on, the relative humidity increases gradually, as the concentration of water in the desiccant increases. The relative humidity reaches $100 \%$ at the end of the specified operating period of 2 hours.

Figure 8 shows air temperature out of the dehumidifier, desiccant temperature at dehumidifier inlet, and desiccant temperature at dehumidifier outlet. The figure shows that 
the desiccant remains almost isothermal over the whole operating period, as a consequence of the high thermal conductivity of the plate material (aluminum). As previously discussed, this simplifies the regeneration process, but reduces the performance of the dehumidifier.

\section{CONCLUSIONS}

A desiccant dehumidifier system has been described and analyzed. The results indicate that the system has advantages over conventional systems for heating EVs. Some of these advantages are listed next:

1. The dehumidifier substantially reduces the heating load for a vehicle. Reduction in heating load is substantially greater than what can be achieved with a regenerator. Heating load is reduced to a level in which waste heat may provide most of the required energy, so that the vehicle may require very little additional heating.

2. The dehumidifier has a reasonable weight and volume for packaging inside an EV.

Dehumidifier weight and volume are comparable to those for regenerators or combustion heaters, while offering significant performance, convenience and emission reduction advantages over these options.

3. The overall energy consumption by the dehumidifier is less than the energy used by conventional methods of heating the car.

The present paper has shown a conceptual design of a desiccant dehumidifier used for heating EVs. Future issues remain to be solved, including: a better selection for desiccant materials; the applicability of these systems for range extenders and series hybrid vehicles; and for $\mathrm{EV}$ air conditioning. 


\section{REFERENCES}

1. Aceves, S.M., 1996, "An Analy tical Companison of Adsorption and Vapor Compression Air Conditioners for Electric Vehicle Applications" Accepted for Publication, ASME Joumal of Energy Resources Technology.

2. Aceves, S.M., and Smith, J.R, 1995, "A Hy brid Vehicle Evaluation Code and Its Application to Vehicle Design," SAE Paper 950491.

3. American Society of Heating Refrigerating and Air Conditioning Engineers, 1981,

"ASHRAE Fundamentals Handbook," ASHRAE, Atlanta, GA.

4. Automotive News, 1993, "Fuel-Burning Heaters Allowed in California Zero Emission Vehicles,"January 25.

5. Burba, J.C., Spiteri, R., and Louch, R., 1995, "The Ford Ecostar: A Thermally Managed Vehicle," Proceedings of the Sustainable Transportation '95 Conference, Northeast Sustainable Energy Association.

6. Charoensupay a, D., and Worek, W.W, 1988, "Parametric Study of an Open-Cyde Adiabatic, Solid, Desiccant Coding Sy stem," Energy, Vol. 13, No. 9, pp. 739-747.

7. Dieckmann, J., and Mallory, D., 1991, "Climate Control for Electric Vehicles," SAE Paper 910250.

8. Dieckmann, J., and Mallory, D., 1992, "Variable Speed Compressor, HFC-134a Based Air Conditioning Sy stem for Electric Vehicles," SAEPaper 920444.

9. Dupont, M., Celestine, B., Nguy en, P.H., Merigoux, J., and Brandon, B., 1994, "Desiccant Solar Air Conditioning in Tropical Climates: I-Dy namic Experimental and Numerical Studies of Silica Gel and Activated Alumina," Solar Energy, Vol. 52, No. 6, pp.509-517.

10. Feustel H., de Almeida, A, Blumstein, C., 1992, "Alternatives to Compressor Cooling in Residence," Energy and Buildings, Vol. 18, pp. 269-286.

11. Freedman, M., and Zemke, B, "Cold Weather Update - GM Impact," Proceedings of the Sustainable Transportation '95 Conferenœ, Northeast Sustainable Energy Association.

12. Haney, S.W., Barr, W.L., Crotinger, J.A., Perkins, L.J., Solomon, C.J., Chaniotakis, E.A., Freidberg J.P., Wei, J, Galambos, J.D., and Mandrekas, J., 1995, "A SUPERCODE for Sy stem Analy sis of Tokamak Experiments and Reactors," Fusion Technology, Vol. 21, p. 1749. 
13. Ikeda, S., Yoshii, Y., and Tamura Y., 1990, "Air Conditioning Electric Vehicles with an Electronically Diven Variable Speed Scroll Ty pe Compressor," SAE Paper 901738.

14. Kays, W.M., and London, A.L., 1964, "Compact Heat Exchangers," McGraw-Hill, New York

15. Kweller, E., Mei, V.C., and Chen, F.C., 1991, "Options of Desiccant Cooling and Dehumidification Technology," Proceedings of the International Energy Conversion Engineering Conference, Vol. 2, pp. 566-570.

16. Kyle, D.M., and Sulivan, RA., 1993, "Heating Ventilation and Air Conditioning Sy stems," US Department of Energy Report, under Contract No, DE-AC05-84OR21400.

17. Mei, V.C., Chen, F.C., Lavan, Z., Collier, R.K, and Meckler, G., 1992, "An Assessment of Desiccant Cooling and Dehumidification Technology," Oak Ridge National Laboratory Repart ORNL/CON-309, Oak Ridge, TN, July.

18. Nimmo, B.G., Collier, R.K., and Rengarajan, K., 1993, "DEAC: Desiccant Enhancement of Cooling-Based Dehumidification," ASHRAE Transactions: Sy mp osia, pp. 842-848.

19. Roy, D, and Gidaspow, D., 1974, "Nonlinear Coupled Heat and Mass Exchange in a Cross-Flow Regenerator," Chemical Engneering Science, Vd. 29, pp. 2101-21 14.

20. Shelton, S.V, 1986, “Solid Adsorbent Heat Pump System," U.S. Patent 4610148.

21. Shimizu S., Hara, H., and Asakawa, F., 1982, "Analy sis on Air-Conditioning Heat Load of Passenger Vehicle," JSAE Review, November, pp. 80-90.

22. Suzuki, N., and Takahashi, T., 1995, "Dehumidify ing-Ty pe Heat Pump Sy stem for Electric Vehicles," Proceedings of the Second Vehide Thermal Management Sy stems Meeting SAE/MMECHE, London, England. pp. 365-369.

23. Suzuki, T., and Ishï, K., 1996, "Air Conditioning System for Electric Vehicle," SAE Paper 960688.

24. Wy czalek, F.A., 1993, "Heating and Cooling Battery Electric Vehicles-the Final Barrier," Proceding of the Intemational Energy Conversion Engineering Conference, Vo. 2, pp. 267272.

25. Zheng W., Worek, WM., and Novosel, D., 1993, "Control and Optimization of Rotational Speeds for Rotary Dehumidifiers," Ashrae Transactions: Sy mposia, pp. 825-833. 
Table 1. Parameters for EV heating load calculations

Ambient air relative humidity, $\% \quad 100$

Comfort temperature, ${ }^{\circ} \mathrm{C}$

23

Number of passengers inside the vehicle

Sensible metabolic heat generation per passenger, $W$

4

Latent metabolic heat generation per passenger, $\mathrm{W}$

75

Vehicle window area, $\mathrm{m}^{2}$

75

Outdoor heat transfer coefficient, $\mathrm{W} / \mathrm{m}^{2 \circ} \mathrm{C}$

3

Indoor heat transfer coefficient, $\mathrm{W} / \mathrm{m}^{2 \circ} \mathrm{C}$

60

Minimum amount of outdoor make-up air per passenger, $\mathrm{kg} / \mathrm{s}$

5

Conduction heat transfer load at $0^{\circ} \mathrm{C}$

0.008

$400 \mathrm{~W}^{1}$

1. Does not include heat transfer through the windows. 
Table 2. Independent variables and their range for the optimization study.

\begin{tabular}{|c|c|c|}
\hline variable & description & allowable range \\
\hline a & $\begin{array}{l}\text { dehumidifier dimension, measured perpendicular } \\
\text { to both the direction of air flow and the desiccant } \\
\text { plates }\end{array}$ & $0.10 m-0.50 m$ \\
\hline b & $\begin{array}{l}\text { dehumidifier dimension, measured along the } \\
\text { direction of air flow }\end{array}$ & $0.10 m-0.50 m$ \\
\hline c & $\begin{array}{l}\text { dehumidifier dimension, measured parallel to the } \\
\text { desiccant plates and perpendicular to the direction } \\
\text { of air flow }\end{array}$ & $0.10 \mathrm{~m}-0.50 \mathrm{~m}$ \\
\hline $\mathbf{n}$ & number of parallel plates in the dehumidifier & unbounded \\
\hline
\end{tabular}


Table 3. Fixed dehumidifier parameters

desiccant layer thickness, $e_{1}, m$

0.002

aluminum plate thickness, $e_{2}, m$

0.0005

desiccant regeneration temperature, ${ }^{\circ} \mathrm{C}$

80

desiccant heat of adsorption, $q_{d}, k J / k g$

2700

daily period of operation, hours

2

ambient temperature, ${ }^{\circ} \mathrm{C}$

fan power, $W$

0 and -10

50 
Table 4. Optimum desiccant dehumidifier design parameters

\begin{tabular}{|c|c|c|}
\hline Parameter & $0^{\circ} \mathrm{C}$ & $-10^{\circ} \mathrm{C}$ \\
\hline dehumidifier dimension a, $\mathrm{m}$ & 0.163 & 0.226 \\
\hline dehumidifier dimension $b, m$ & 0.132 & 0.186 \\
\hline dehumidifier dimension $\mathbf{c}, \mathbf{m}$ & 0.5 & 0.5 \\
\hline number of parallel plates $n$ & 26 & 35 \\
\hline dehumidifier volume $e^{1}$, liters & ${ }^{\top} 10.8$ & 21.0 \\
\hline total desiccant mass, $\mathrm{kg}$ & 14.1 & 26.8 \\
\hline total aluminum mass, $\mathrm{kg}$ & 2.26 & 4.40 \\
\hline dehumidifier mass ${ }^{1}, \mathrm{~kg}$ & 16.41 & 31.3 \\
\hline distance between plates $s, m$ & 0.00626 & 0.00646 \\
\hline free space for air flow $\mathrm{d}, \mathrm{m}$ & 0.00177 & 0.00196 \\
\hline Reynolds number $\operatorname{Re}$ & 1217 & 1044 \\
\hline air mass flow rate $\mathrm{m}_{\mathrm{a}}, \mathrm{kg} / \mathrm{s}$ & 0.148 & 0.171 \\
\hline number of heat transfer units, NTU & 1.44 & 2.13 \\
\hline initial desiccant humidity ratio $\mathrm{w}_{\mathrm{d}, \mathrm{o}}, \mathrm{kg} / \mathrm{kg}$ & 0.00713 & 0.00303 \\
\hline final average desiccant humidity ratio $\mathrm{w}_{\mathrm{d}, \mathrm{f}} \mathrm{kg} / \mathrm{kg}$ & 0.0857 & 0.0388 \\
\hline total amount of water adsorbed, $\mathrm{kg}$ & 1.11 & 0.960 \\
\hline energy required for regeneration, $\mathrm{kWh}$ & 1.28 & 1.59 \\
\hline heating load reduction over conventional system ${ }^{2}, \mathrm{kWh}$ & 3.64 & 5.23 \\
\hline
\end{tabular}

1. Includes only desiccant-aluminum plates. Does not include external cover, insulation, fan or other accessories.

2. Calculated at design conditions during a trip lasting 2 hours. 


\section{FIGURE CAPTIONS}

Figure 1. Window temperature required to avoid condensation as a function of make-up outdoor air flow rate, for an ambient temperature of $5^{\circ} \mathrm{C}$ and 4 passengers inside the vehicle.

Figure 2. Ventilation heating load, window heat transfer, and total heating load, as a function of outdoor air ventilation rate, for an ambient temperature of $5^{\circ} \mathrm{C}$ and 4 passengers inside the vehicle.

Figure 3. Minimum total heating load, along with the corresponding outdoor air ventilation and window conduction contributions, as a function of ambient temperature.

Figure 4. Minimum total heating loads as a function of ambient temperature, for the case with no regeneration (from Figure 3), as well as for the three selected values of the regenerator effectiveness $(50,60$ and $70 \%)$.

Figure 5. Heating loads for the EV equipped with the dehumidifier, as a function of ambient temperature, with and without regeneration. Three values are used for regenerator effectiveness $(50,60$ and $70 \%)$. Minimum heating load for the vehicle with no dehumidifier is also included for comparison (from Figure 3).

Figure 6. Schematic of the desiccant dehumidifier plates being analyzed.

Figure 7. Relative humidity of the air inside the car and the air flowing out of the dehumidifier as a function of time during vehicle operation. Relative humidity in this figure is defined as partial pressure of water divided by partial pressure of water at saturated conditions, at the temperature of the windows. According to this definition, a relative humidity of less than $100 \%$ indicates that no condensation occurs on the windows.

Figure 8. Air temperature out of the dehumidifier, desiccant temperature at dehumidifier inlet, and desiccant temperature at dehumidifier outlet as a function of time during vehicle operation. 
Figure 1.

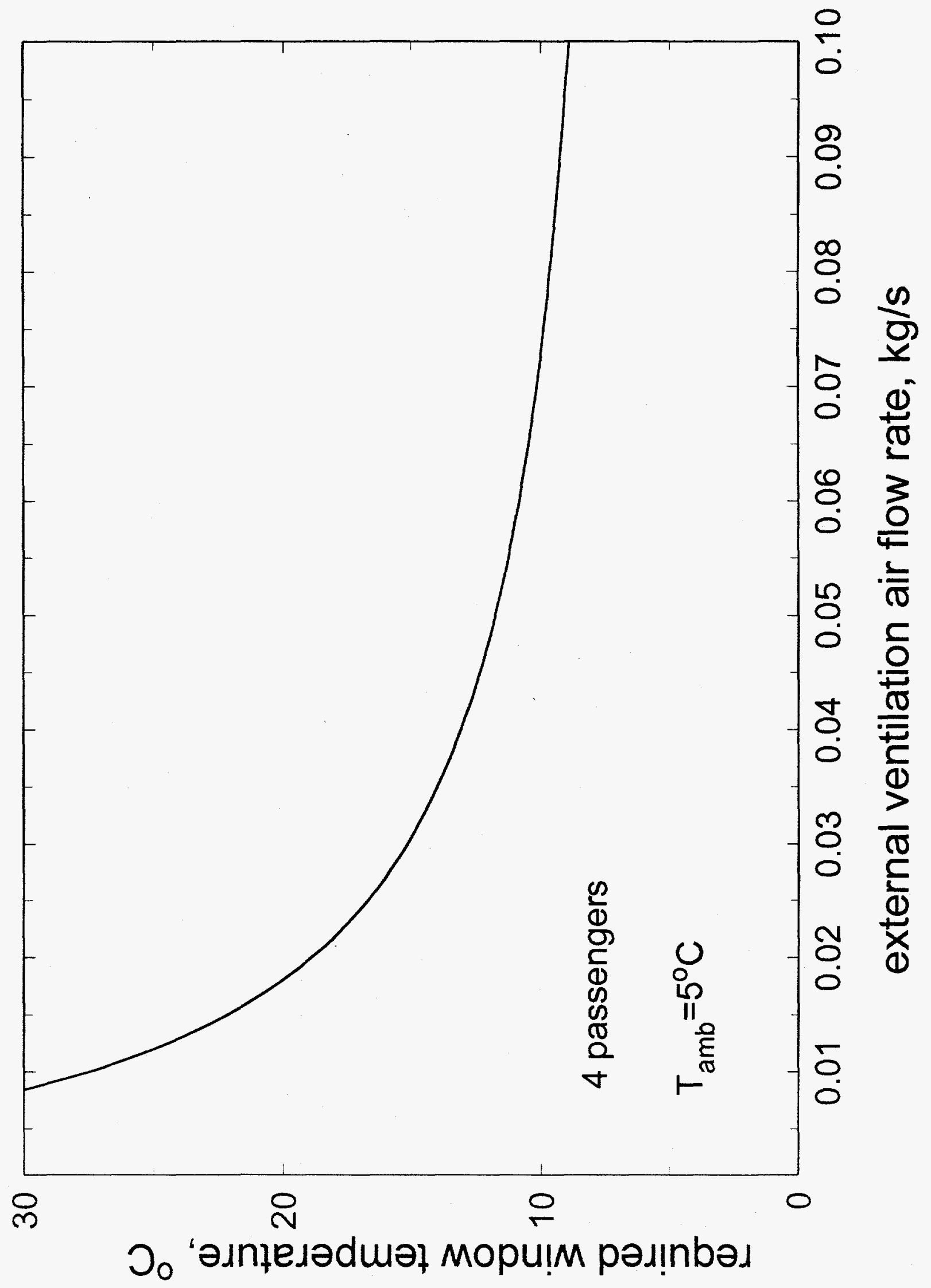


Figure 2.

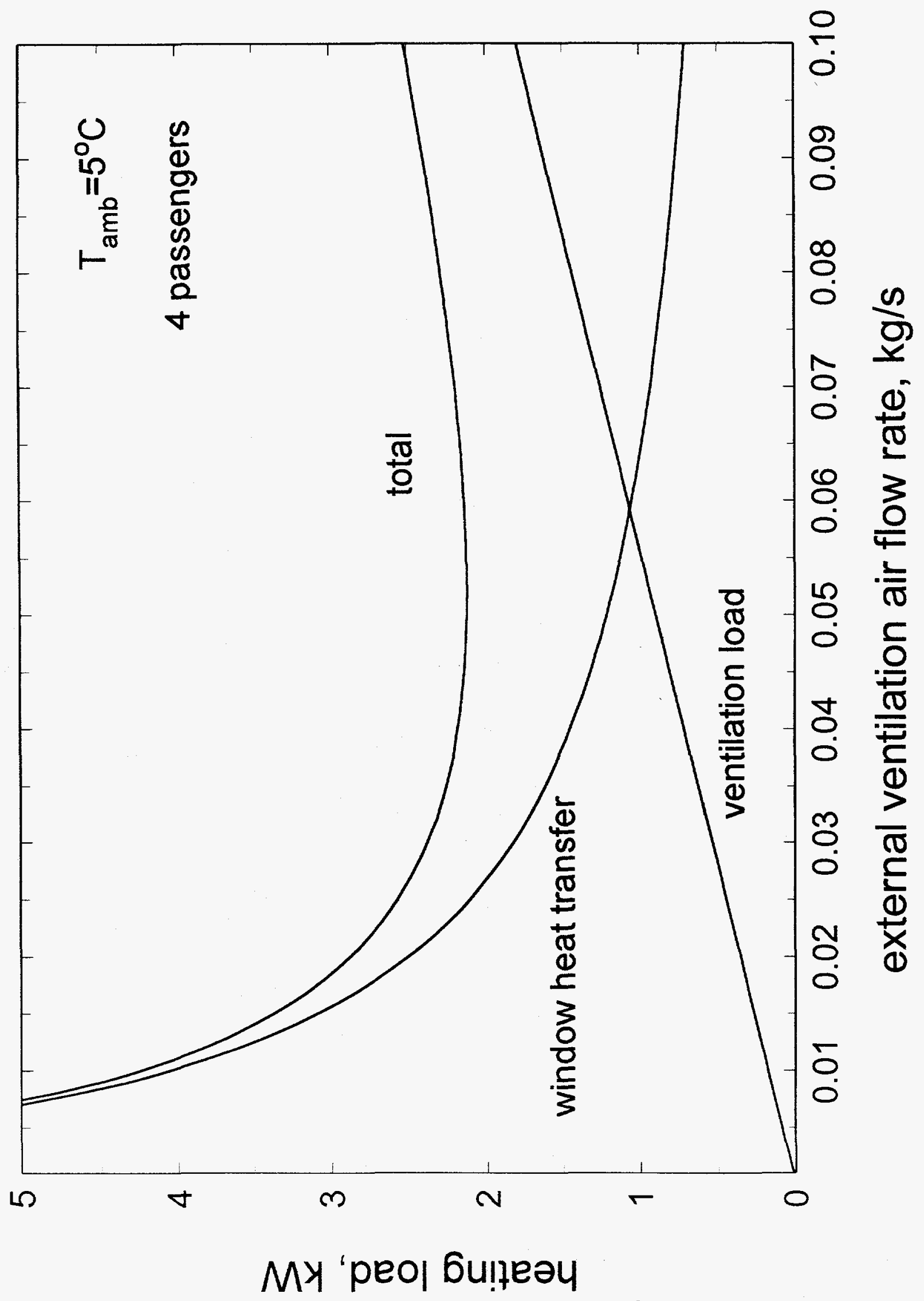


Figure 3.

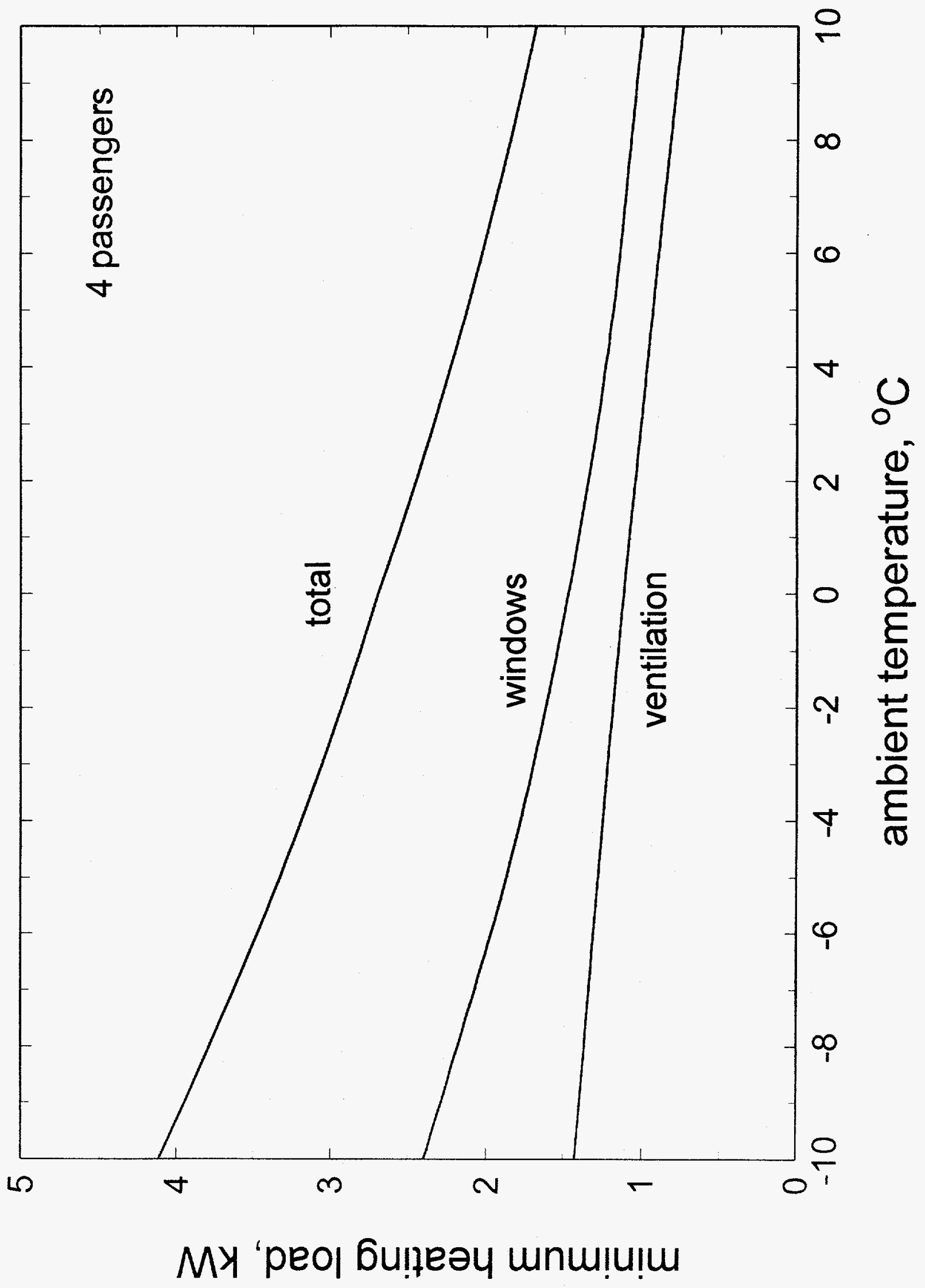




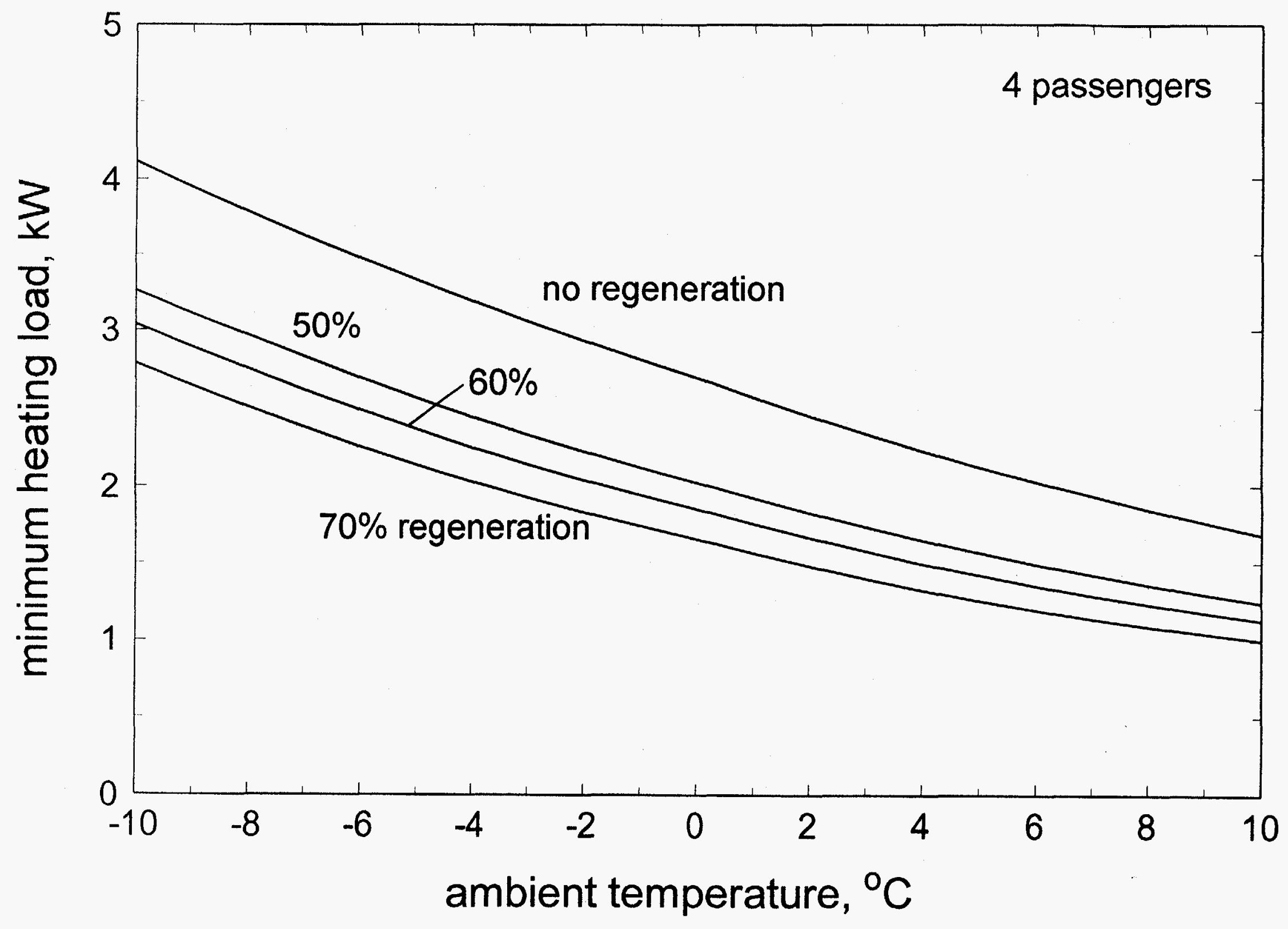


Figure 5.

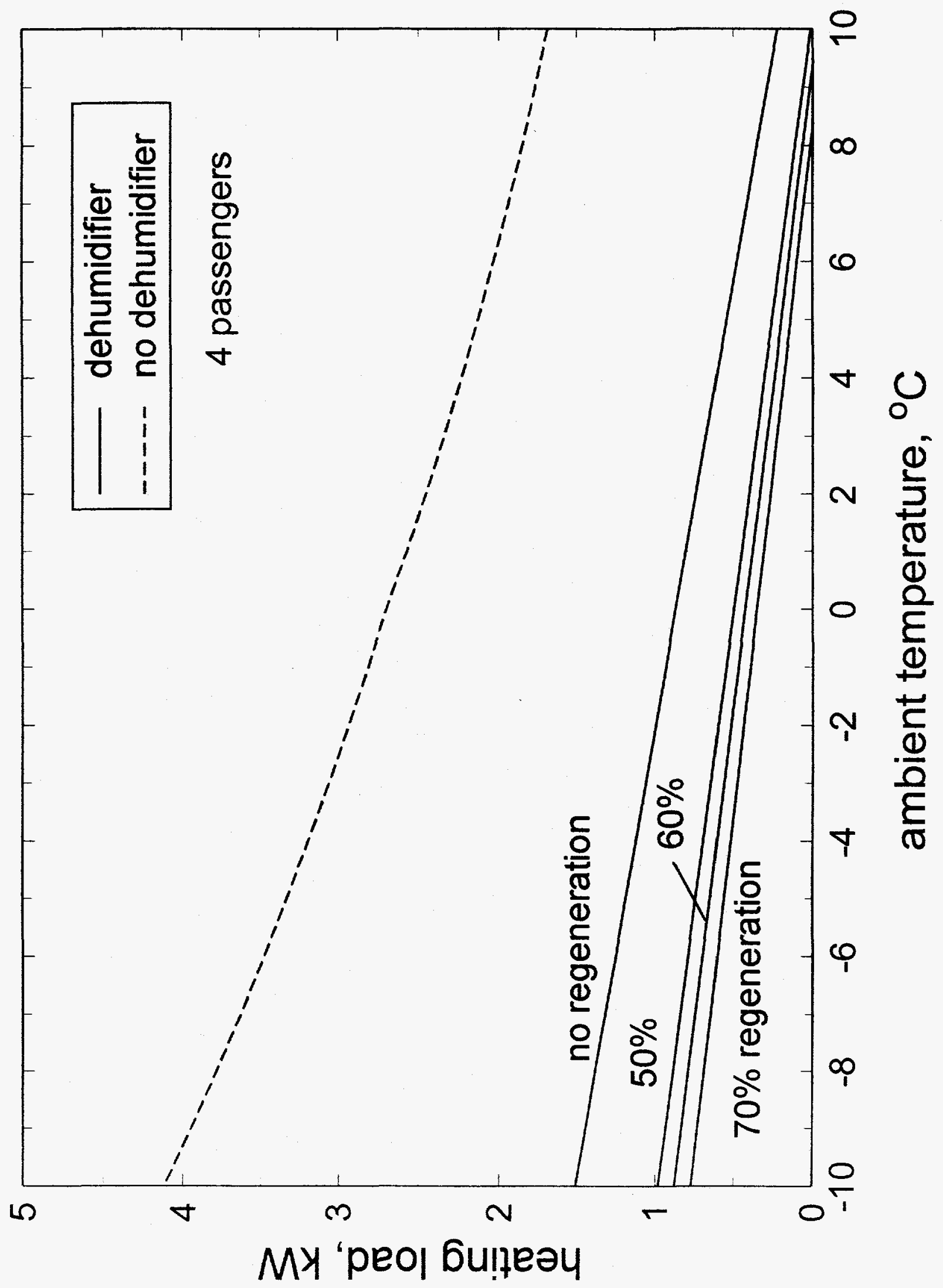


Figure 6.

$-\left|a^{-1}\right|-0 \rightarrow-\left|\omega^{2}\right|-$

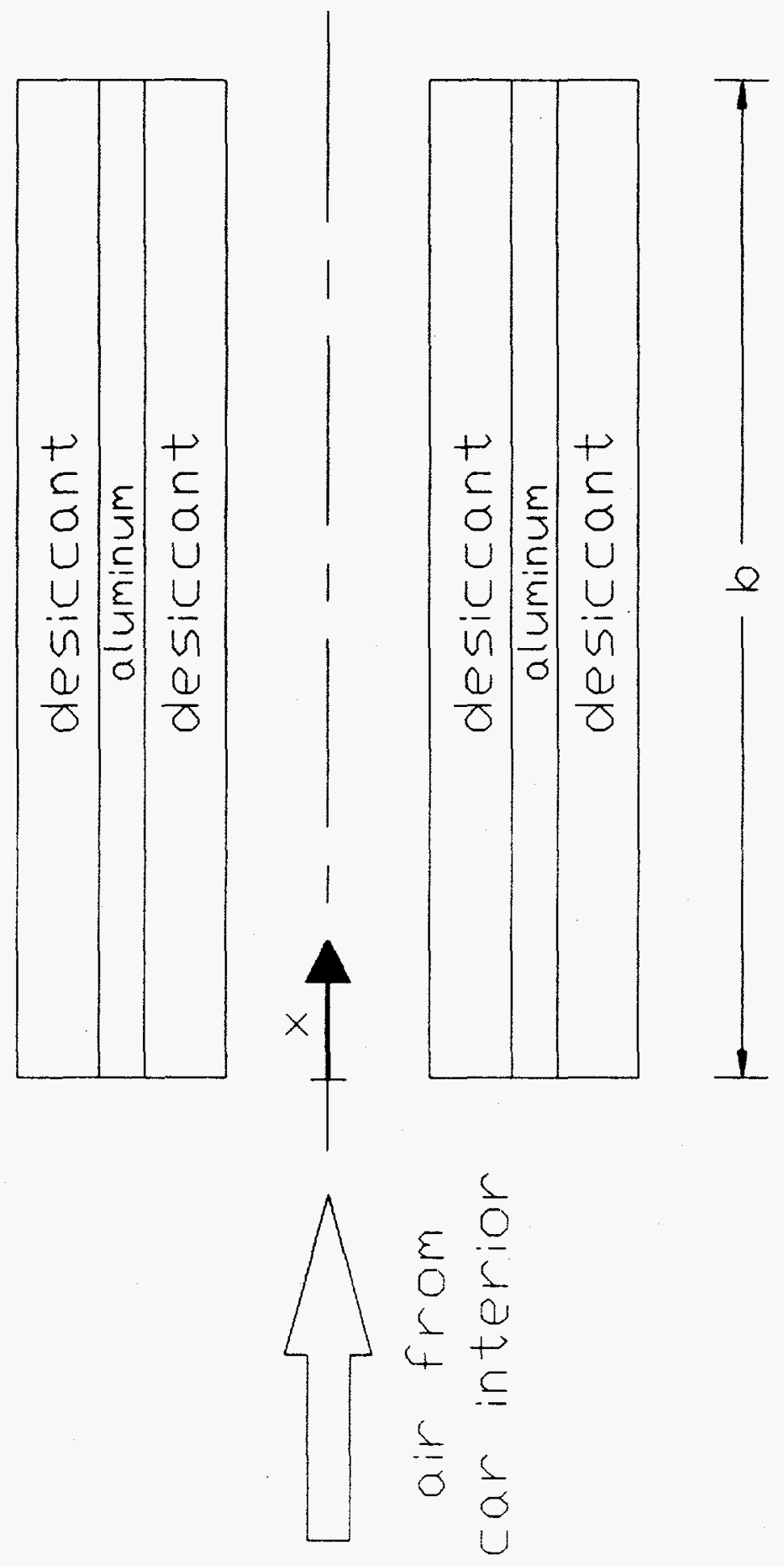


Figure 7.

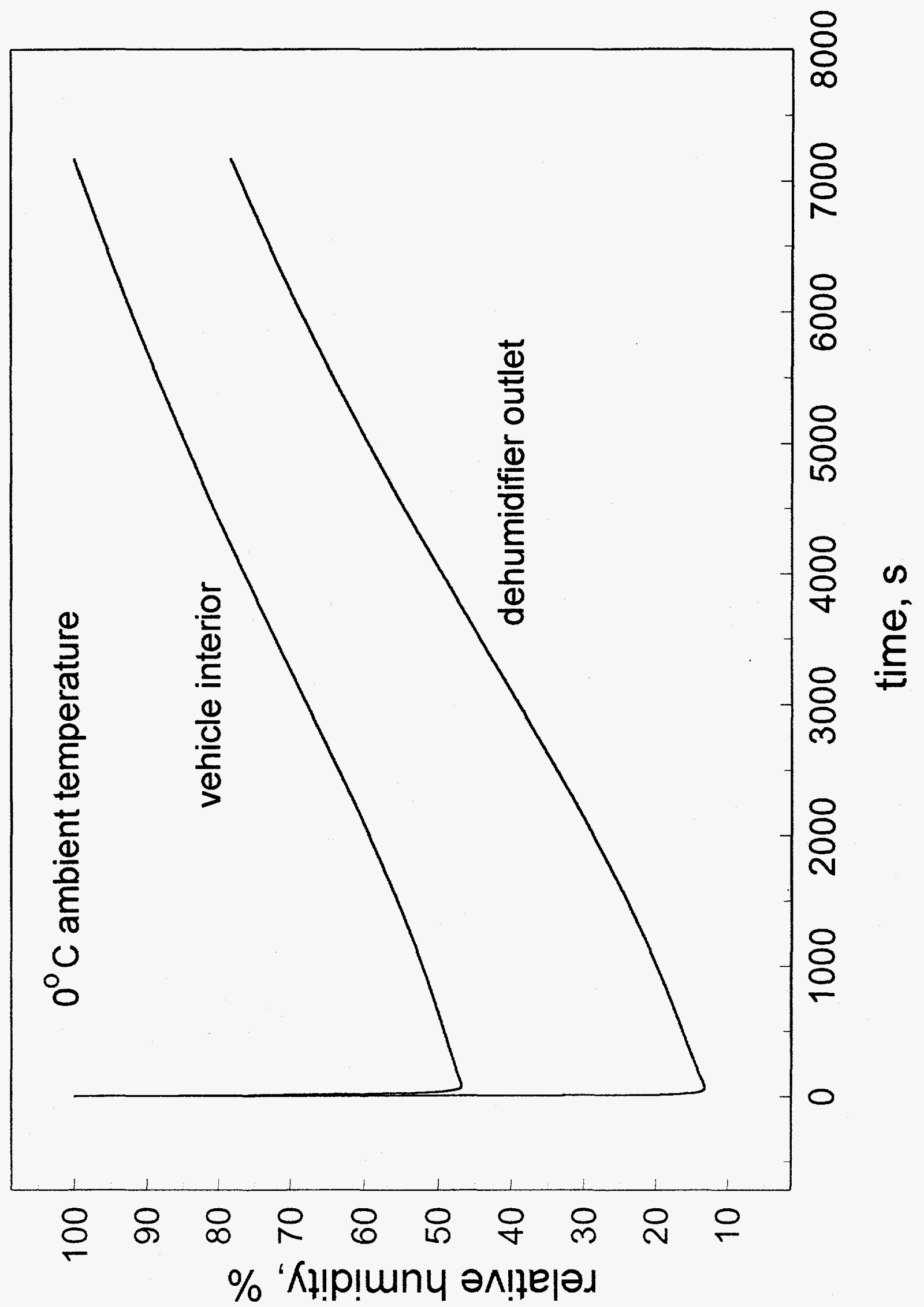




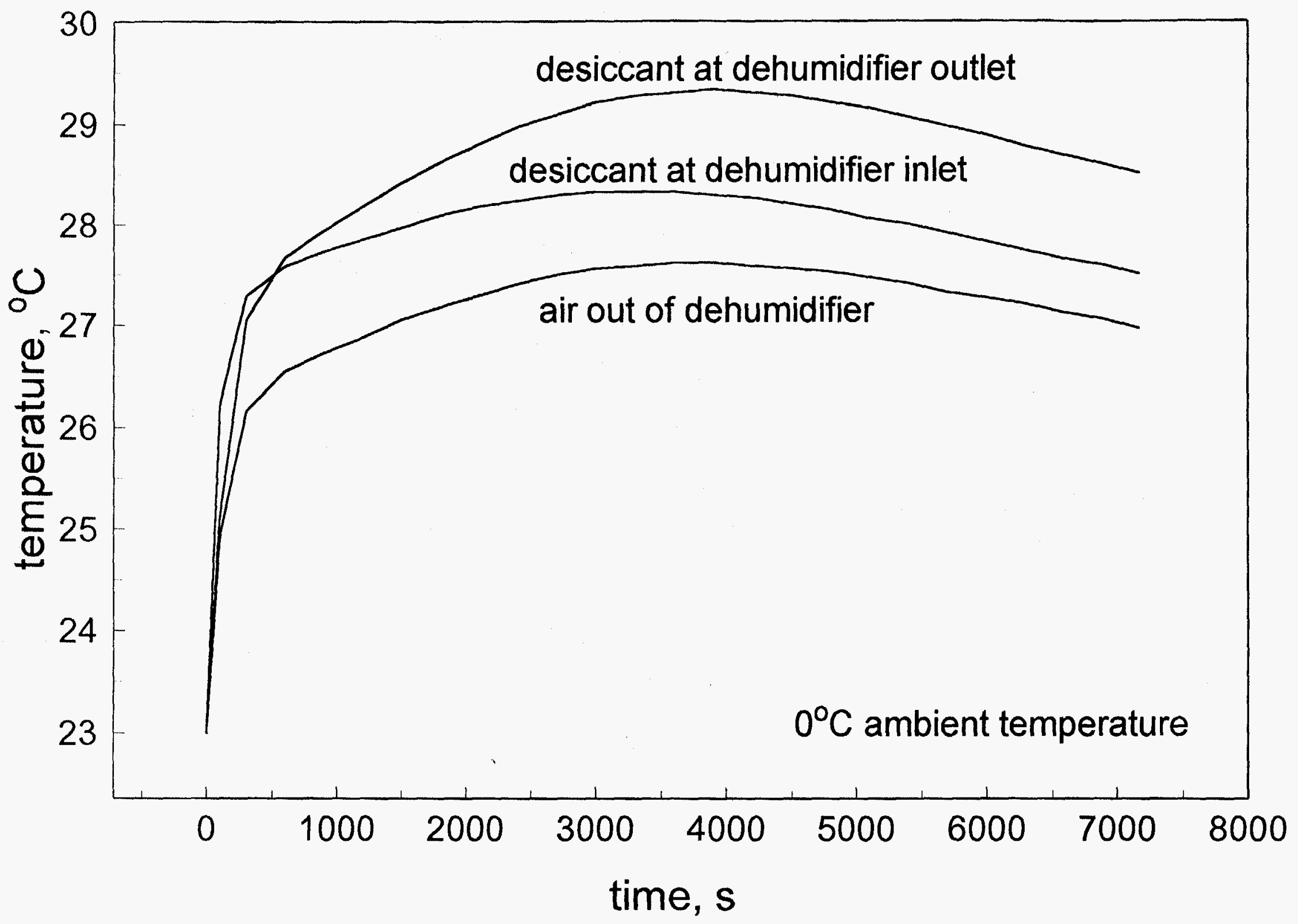

